\title{
Producing hydrogen-rich gas by fresh biomass co-pyrolysis with additive
}

\author{
Zhang B. ${ }^{1,2}$, Zhan L. ${ }^{2,}{ }^{*}$ Yang Z. ${ }^{2}$, Yan Y. ${ }^{2}$, Ran J. ${ }^{2}$ and Guo M. ${ }^{2}$ \\ ${ }^{1}$ Institute for Energy Research, Jiangsu University, Zhenjiang, 212013, P.R.China \\ ${ }^{2}$ College of Power Engineering, Chongqing University, Chongqing, 400044, P.R.China \\ Received: 26/120/2014, Accepted: 16/12/2016, Available online: 14/02/2017 \\ *to whom all correspondence should be addressed: \\ e-mail: lizhang_cqu@163.com
}

\begin{abstract}
Pyrolysis properties of fresh ficus lacor leaves with moisture content of $70 \mathrm{wt}$. \% was investigated in a TGA setup. The effects of different operating parameters on pyrolysis of biomass were studied in a fixed-bed reactor system. With addition of $\mathrm{CaO}$, there showed an additional decrease in weight at temperature range of $382 \sim 490{ }^{\circ} \mathrm{C}$, but $12 \mathrm{wt}$. \% weight was recovered in the first stage $\left(40^{\sim} 220^{\circ} \mathrm{C}\right)$. Fresh biomass pyrolysis was calculated to be first order reaction with activation energy about 29.8 $\mathrm{kJ} \mathrm{mol}^{-1}$. Activation energy was lowered to $20.4 \mathrm{~kJ} \mathrm{~mol}^{-1}$ by addition of $\mathrm{CaO}$. With scope of temperature studied, higher temperature was found always favor hydrogen production during pyrolysis of fresh biomass. Carbonation and hydration of $\mathrm{CaO}$ enhanced water gas shift reaction (WGS) which led to hydrogen yield increasing. The highest hydrogen content (around 70vol. \%) of hydrogen concentration and hydrogen yield $\left(23.2 \mathrm{ml} \mathrm{g}^{-1}\right.$-biomass $)$ were achieved when $\mathrm{CaO} /$ biomass mass ratio increased to 0.3 . Pyrolysis of fresh biomass without pre-drying showed the potential of hydrogen production.
\end{abstract}

Keywords: Fresh biomass; Pyrolysis; $\mathrm{CaO}$; NiO; Hydrogen

\section{Introduction}

Biomass plays an irreplaceable role in the energy world, for it is renewable and abundant. Thermochemical conversion is one of the most important conversion technologies of biomass. Through thermochemical treatment, biomass is decomposed to bio-oil, char, syngas and syngas mainly consists of $\mathrm{H}_{2}, \mathrm{CO}, \mathrm{CO}_{2}$, and $\mathrm{CH}_{4}$ (Nasir Uddin et al., 2013). Hydrogen is thought to be the energy for future. It is being used in various transports, industrial, commercial and residential applications, where fossil fuels are currently used. High content of hydrogen can be produced by pyrolysis of biomass, and this technology is now attracting much attention (Ansari et al., 2014; Liu et al., 2014; Alvarez et al., 2014).

However, traditional pyrolysis of biomass involves some problems: lower hydrogen, higher tar and residue char content. To overcome these disadvantages, catalytic pyrolysis was proposed. By using catalyst, condensable gas can reach the active sites of the catalyst, and the $\mathrm{C}-\mathrm{H}$ bonds of the heavy hydrocarbons will be weaken which leads to cracking and reforming reactions happen in a more readily way. Hydrogen yield was promoted due to the enhanced shifting of $\mathrm{H}$ element from hydrocarbons to the target product. Several catalysts were reported to be effective in elimination of tar during pyrolysis of biomass (Bulushev and Ross, 2011). Jiang et al. (2012), conducted pyrolysis of biomass in molten alkali media. $\mathrm{NiMo} / \mathrm{Al}_{2} \mathrm{O}_{3}$ catalyst was used during pyrolysis of biomass by Hao et.al (2010). $\mathrm{ZnCl}_{2}$, $\mathrm{K}_{2} \mathrm{CO}_{3}$ and $\mathrm{NaCO}_{3}$ were used as catalyst during pyrolysis of olive husk, and it was found that using about $17 \mathrm{wt}$. $\% \mathrm{ZnCl}_{2}$ at about $752^{\circ} \mathrm{C}$ obtained largest hydrogen rich gas yield (Çağlar and Demirbaş, 2002). Corella et al. (2004) employed nickel-based monoliths for tar elimination in fuel gas produced by biomass gasification in a fluidized bed at a small pilot-plant scale. Recently, two different sorbents, $\mathrm{CaO}$ and $\mathrm{CaO} \cdot \mathrm{MgO}$ were evaluated and upgraded bio-oils were obtained in both cases (Veses et al., 2014). It was also reported that addition of $\mathrm{CaO}$ could enhance the gaseous production and increased the production of hydrogen from pyrolysis of biomass (Kuan et al., 2013), and Zhang et al. (2014) reported that $\mathrm{CaO}$ from different precursors had different impact on biomass pyrolysis.

By now, most of the studies on biomass thermochemical conversion used biomass with low moisture content. However, most of the available biomass are with high moisture and researches on conversion of biomass directly without pre-drying are still not enough. Also, some authors believe that $\mathrm{H}_{2} \mathrm{O}$ would influence the sorbent performance on $\mathrm{CO}_{2}$ capture which may further makes a non-ignorable effect on biomass pyrolysis (Zhang et al., 2014). The aim of this paper is to study the pyrolysis properties of the biomass rich in water especially with additives. In this paper, pyrolysis of fresh ficus lacor leaves with moisture content as high as $70 \mathrm{wt}$. \% was investigated, and also the effect of additive ( $\mathrm{CaO}$ and $\mathrm{NiO}$ ) on pyrolysis was tested. Kinetic studies were conducted in a TGA setup. The influence of pyrolysis temperature, additive type, and additive loading on gas composition and hydrogen yield were studied in a bench scale fixed-bed reactor system. 


\section{Materials and Methods}

\subsection{Sample preparation}

Ficus lacor is widely available in Southwest of China. The ficus lacor leaves were freshly collected, and sliced to the shape of square with side length of about $0.5 \mathrm{~cm}$. Without drying, fresh leaf contains $70 w t$. \% moisture. Based on airdried basis, it owned volatiles content of $60.37 \mathrm{wt}$. \%, fixed carbon content of $13.2 \mathrm{wt}$. \% and ash content of $1.33 \mathrm{wt}$. \%. $\mathrm{CaO}$ and $\mathrm{NiO}$ were all analytical reagents with more than 99.9\% purity (Sinopharm Chemical Reagent Beijing Co., Ltd.). A mixture of $\mathrm{CaO}$ and $\mathrm{NiO}(\mathrm{CaO} / \mathrm{NiO})$ was prepared by physically mixing of both compounds at a mass ratio of one. Before pyrolysis experiments, all additives were totally calcined at $800{ }^{\circ} \mathrm{C}$ for $3 \mathrm{~h}$ in muff furnace under $\mathrm{N}_{2}$ flow, crushed and sieved to less than 60 mesh. Catalytic effects of $\mathrm{CaO}, \mathrm{NiO}, \mathrm{CaO} / \mathrm{NiO}$ on pyrolysis of fresh biomass were investigated in the paper.

\subsection{Experimental apparatus}

Experiments were carried out in a TGA setup (STA409 PC, Germany) to study the pyrolysis characteristics of fresh biomass. $50 \mathrm{mg}$ of biomass was used in each test and for the case with additive the amount of additive was $15 \mathrm{mg}$. Flow rate of carrying gas was $30 \mathrm{ml} \mathrm{min}^{-1}\left(\mathrm{~N}_{2}\right)$ and protecting gas was $20 \mathrm{ml} \mathrm{min}^{-1}\left(\mathrm{~N}_{2}\right)$. Temperature rose with a rate of $20{ }^{\circ} \mathrm{C} \mathrm{min}-1$ from room temperature to $800{ }^{\circ} \mathrm{C}$ during the test in TGA.

Pyrolysis of fresh biomass was also conducted in a fixedbed system to investigate the syngas composition, as schematically showed in Fig. 1. The experimental apparatus consists of a gas supply unit, an electrical furnace, a vertical stainless steel reactor, an ice bath for water and tar elimination, a dryer for totally wiping off moisture and a gas bag for sampling syngas. The redundant syngas was ignited in air. The stainless steel reactor $(120 \mathrm{~cm}$ in length, $30 \mathrm{~mm}$ I.D.) was placed in the electrical furnace vertically. A plastic tank filled with ice water was used as ice bath, and the first wash bottle was filled with deionized water and another one was filled with some acetone. After the syngas went through a drier, it was collected in a 1 I sample bag.

During the test in fixed-bed, $3 \mathrm{~g}$ biomass was used in each experiment and $10 \mathrm{ml} \mathrm{min}^{-1}$ of $\mathrm{N}_{2}$ was used as carrying gas. Defined amount of additive was physically mixed with biomass sample before test, and then loaded into the vertical stainless steel reactor. The temperature in the reactor started from room temperature to desired pyrolysis temperature at a heating rate $15 \sim 19{ }^{\circ} \mathrm{C} \mathrm{min}^{-1}$. Syngas was collected when temperature reached $250{ }^{\circ} \mathrm{C}$, and the total collection time was $20 \mathrm{~min}$ for each test. The product gas was analyzed in gas chromatograph (GC). The GC was equipped with a TCD detector, with $60 \mathrm{ml} / \mathrm{min} \mathrm{He}$ (purity of 99.999\%) as carrying gas. The temperature of gasify room, column and detector were $120^{\circ} \mathrm{C}, 60^{\circ} \mathrm{C}$ and $180^{\circ} \mathrm{C}$, respectively. $10 \mathrm{ml}$ of the syngas was injected into the gasify room of the $\mathrm{GC}$ for each test by using syringe and external standard method was used to calculate the relative concentration of component gas. The concentrations of $\mathrm{CO}, \mathrm{CO}_{2}, \mathrm{CH}_{4}$, and $\mathrm{H}_{2}$ were finally determined by TCD-GC.

The yield of hydrogen ( $\mathrm{ml} \mathrm{g}^{-1}$-biomass) was calculated using the following equation:

$$
\text { Hydrogen yield }=\frac{V^{*} t}{\Phi_{\mathrm{N}}} * \frac{\Phi_{\mathrm{H}}}{\mathrm{m}}
$$

Where $\mathrm{V}, \mathrm{t}, \Phi_{\mathrm{H}}, \Phi_{\mathrm{N}}, \mathrm{m}$ represents the flow rate of $\mathrm{N}_{2}$, gas collection time, concentration of $\mathrm{H}_{2}$, concentration of $\mathrm{N}_{2}$ and weight of biomass, respectively.

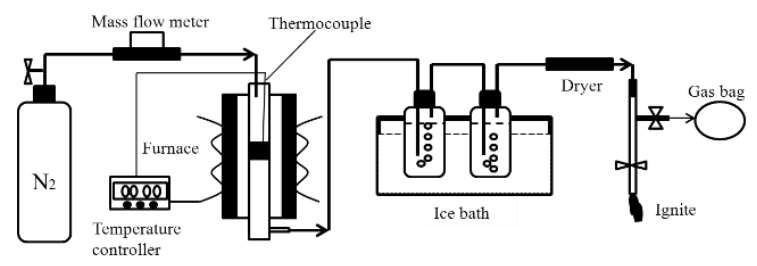

Figure 1. Schematic diagram of fixed-bed reactor system

\subsection{Pyrolysis Kinetics}

The non-isothermal kinetics equation for solid decomposition reaction can be written as follow:

$$
\frac{\mathrm{da}}{\mathrm{dt}}=\mathrm{kf}(\mathrm{a})
$$

Where

$$
a=\frac{m_{0}-m_{t}}{m_{0}-m_{f}}
$$

In Eq. (3), $m_{0}, m_{t}$ and $m_{f}$ represent the initial, instantaneous and final weight of the sample, respectively. The rate constant $k$ can be expressed by the Arrhenius equation:

$$
k=A_{0} \exp \left(\frac{-E}{R T}\right)
$$

And here the mechanism function $f(a)$ is used as follow:

$$
f(a)=(1-a)^{n}
$$

Plugging Eq. (4) and Eq. (5) into Eq. (2), we have:

$$
\frac{d a}{d t}=A_{0} \exp \left(-\frac{E}{R T}\right)(1-a)^{n}
$$

For, $\beta=d T / d t$ Eq. (6) can be re-written as:

$$
\frac{\mathrm{da}}{\mathrm{dt}}=\frac{\mathrm{A}_{0}}{\beta} \exp \left(-\frac{\mathrm{E}}{\mathrm{RT}}\right)(1-\mathrm{a})^{\mathrm{n}}
$$

Then, taking a natural logarithm (In) on both sides of Eq. (7) gives:

$$
\ln \frac{\mathrm{da}}{\mathrm{dT}}=\ln \frac{\mathrm{A}_{0}}{\beta}-\frac{\mathrm{E}}{\mathrm{RT}}+\mathrm{n} \ln (1-\mathrm{a})
$$

The kinetic parameters, activation energy, pre-exponential factor, and the reaction order of biomass pyrolysis can be determined by linear fitting of the equation: 


$$
\frac{\Delta \ln \left(\frac{\mathrm{da}}{\mathrm{dT}}\right)}{\Delta \ln (1-\mathrm{a})}=n-\frac{\mathrm{E}}{\mathrm{R}} \frac{\Delta \frac{1}{\mathrm{~T}}}{\Delta \ln (1-\mathrm{a})}
$$

\section{Results and discussion}

\subsection{Pyrolysis characteristic of fresh biomass}

The decomposition property of the fresh biomass was investigated and results were shown in Fig. 2. As can be seen in Fig. 2(a), largest weight loss of biomass was found in the temperature range of $40 \sim 220{ }^{\circ} \mathrm{C}$, and the temperature for the highest decomposition rate was around $140{ }^{\circ} \mathrm{C}$. In this temperature interval, weight loss is mainly from fast release of moisture. The second distinctly weight loss was located in the temperature range of $220^{\sim} 382{ }^{\circ} \mathrm{C}$, and the peak decomposition rate was at temperature of $338{ }^{\circ} \mathrm{C}$. Pyrolysis of hemicellulose, cellulose, and lignin was reported to occur in the following temperature ranges: $150^{\sim 315}, 315^{\sim} 400$ and $250^{\sim 900}{ }^{\circ} \mathrm{C}$, respectively (Nowakowski et al., 2007). It indicates that cellulose and hemicellulose are mainly responsible to the second weight loss in temperature range of $220^{\sim} 382{ }^{\circ} \mathrm{C}$. After that, weight loss curve went down slowly till the end and the DTG curve was leveled off. This period should be resulted from slow decomposition of lignin and gasification of char.

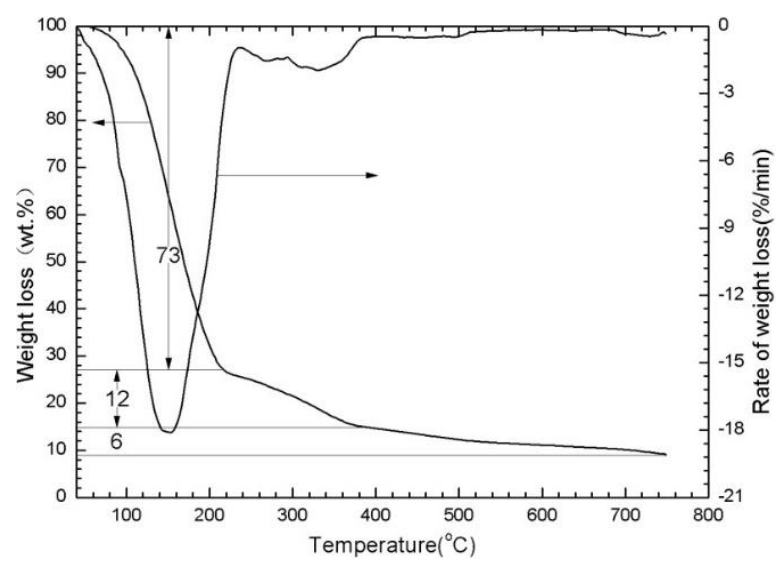

(a)

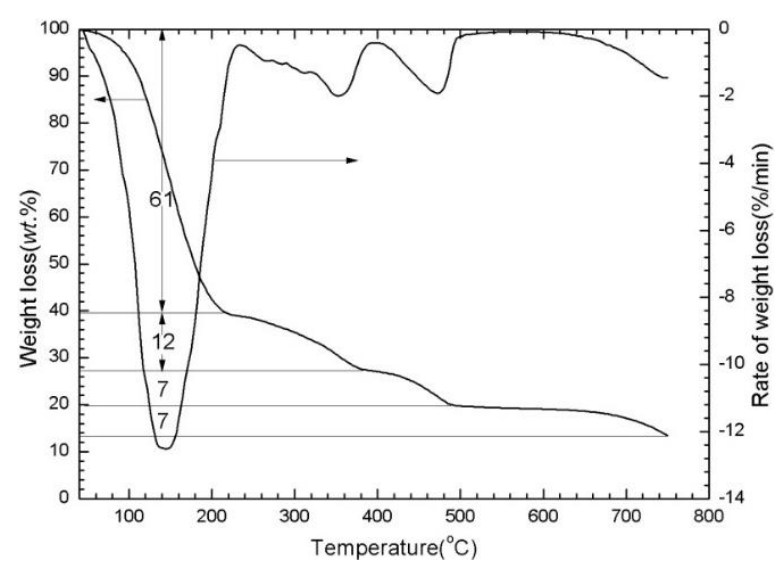

(b)

Figure 2. TG and DTG results of the fresh biomass. (a) Pure biomass; (b) With 30 wt. \% of CaO

From Fig. 2(b), with addition of $\mathrm{CaO}$, the pyrolysis characteristic of fresh biomass was changed. Weight loss in the temperature range of $40 \sim 220^{\circ} \mathrm{C}$ was much lower than that from pure biomass, almost decreased by $12 w t$. \%. Suitable explanation for this observation can be consumption of moisture released from biomass by hydration of $\mathrm{CaO}$ (Eq. (10)) to form $\mathrm{Ca}(\mathrm{OH})_{2}$. Weight loss in the temperature range of $220^{\sim} 382{ }^{\circ} \mathrm{C}(12 w t$. \%) was similar with that of pure biomass. However, there showed an additional fast decrease stage in weight (7wt. \%) at temperature range of $382 \sim 490{ }^{\circ} \mathrm{C}$. That may indicate the happening of the reverse reaction of $\mathrm{Eq}$. (10), for $\mathrm{Ca}(\mathrm{OH})_{2}$ was easy to decompose at temperature higher than $400^{\circ} \mathrm{C}$. The highest decomposition rate was at temperature of $480{ }^{\circ} \mathrm{C}$. The last fast decrease in weight after $700{ }^{\circ} \mathrm{C}$ should 
be related to the beginning of $\mathrm{CaCO}_{3}$ decomposition (the reverse reaction of Eq. (11)).

$$
\begin{aligned}
& \mathrm{CaO}+\mathrm{H}_{2} \mathrm{O} \leftrightarrow \mathrm{Ca}(\mathrm{OH})_{2} \pm 157 \mathrm{~kJ} \mathrm{~mol}^{-1} \\
& \mathrm{CaO}+\mathrm{CO}_{2} \leftrightarrow \mathrm{CaCO}_{3} \pm 178 \mathrm{~kJ} \mathrm{~mol}^{-1}
\end{aligned}
$$

The kinetic calculations were carried out by using Eq. (9), based on the assumption that the Ao was a constant in a given temperature range, and we had only done linear fitting to the main decomposition regions of the biomass (except the moisture release region). The calculation results were shown in Tab. 1 . It can be seen that with addition of $\mathrm{CaO}$ the kinetic parameters were changed. The order of reaction $(n)$ increased from 1.32 to 2.86 when additive was added. Apparent activation energy $(E)$ decreased from $29.8 \mathrm{~kJ} \mathrm{~mol}^{-1}$ to $20.4 \mathrm{~kJ} \mathrm{~mol}^{-1}$ which represents a decrease almost by $31 \%$. On the other hand, the reaction order in the temperature of $382 \sim 490{ }^{\circ} \mathrm{C}$ was 3.04 and with an activation energy of $40.9 \mathrm{~kJ} \mathrm{~mol}^{-1}$.

Table 1. Kinetic parameters calculated from pyrolysis of fresh biomass with or without $\mathrm{CaO}$

\begin{tabular}{ccccc}
\hline Sample & $\begin{array}{c}\text { Temperature } \\
\text { range }\left({ }^{\circ} \mathbf{C}\right)\end{array}$ & $\boldsymbol{n}$ & $\begin{array}{c}\boldsymbol{E} \\
\left(\mathbf{k J ~ m o l} \mathbf{~}^{-1}\right)\end{array}$ & $-\mathbf{R}^{\mathbf{2}}$ \\
\hline Biomass & $220^{\sim 382}$ & 1.32 & 29.8 & 0.99 \\
\hline $\begin{array}{c}\text { Biomass/30 } \\
w t . \% \mathrm{CaO}\end{array}$ & $220^{\sim 382}$ & 2.86 & 20.4 & 0.98 \\
\cline { 2 - 5 } & $382^{\sim} 490$ & 3.04 & 40.9 & 0.89 \\
\hline
\end{tabular}

\subsection{Activity test in fixed-bed reactor system}

Temperature is the major factor that influences the hydrogen production from pyrolysis of biomass. Fig. 3 shows the dry gas composition and hydrogen yield at four pyrolysis temperatures without additive, from 500 to $800{ }^{\circ} \mathrm{C}$ with $100{ }^{\circ} \mathrm{C}$ interval. As can be seen that temperature influences pyrolysis mainly by hydrogen production. Hydrogen concentration and yield increased with increasing of temperature.

$$
\begin{aligned}
& \mathrm{CH}_{4}+\mathrm{H}_{2} \mathrm{O}=\mathrm{CO}+3 \mathrm{H}_{2}-206 \mathrm{~kJ} \mathrm{~mol}^{-1} \\
& \mathrm{Tar}+\mathrm{H}_{2} \mathrm{O} \rightarrow \mathrm{H}_{2}+\mathrm{CO}+\ldots \text { endothermic } \\
& \mathrm{C}+\mathrm{H}_{2} \mathrm{O} \rightarrow \mathrm{CO}+\mathrm{H}_{2}-131 \mathrm{~kJ} \mathrm{~mol}^{-1}
\end{aligned}
$$

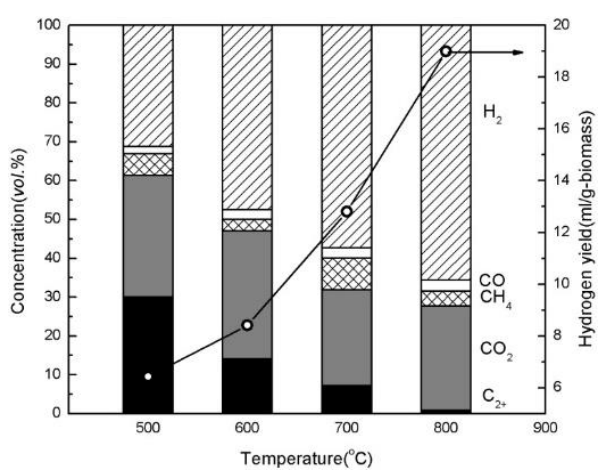

Figure 3. Gas composition and hydrogen yield at different pyrolysis temperatures.

Biomass weight was $3 \mathrm{~g}$, additive/biomass (wt.) was 0 , heating rate was $15^{\sim} 19^{\circ} \mathrm{C} \mathrm{min}^{-1}$
At $800{ }^{\circ} \mathrm{C}$, hydrogen yield was almost 2.8 times and hydrogen concentration was about 2 times more than that at $500{ }^{\circ} \mathrm{C}$. CO content was slightly increased and $\mathrm{CO}_{2}$ content was a little decreased with temperature increasing. It is clear that higher pyrolysis temperature benefited the hydrogen production. Methane steam reforming (Eq. (12)), tar elimination (Eq. (13)) and water gas reaction (Eq. (14)) are all endothermic reactions and can be enhanced by increasing of temperature, which may lead to production of more hydrogen.

There is a wide range of catalysts for pyrolysis and gasification of biomass, mainly consist of three categories including: mineral catalyst, alkali metal catalyst and transition metal catalyst (Sutton et al., 2001). Ni-based catalyst is one of the catalysts that are widely used for its high activity on catalyst of methane steam reforming and elimination of tar. $\mathrm{CaO}$ is abundant and cheap, its usage in gasification and pyrolysis attracted intensive researches recently for the sorption enhanced hydrogen production (SEHP) (Han et al., 2011). It was also reported that $\mathrm{CaO}$ had catalysis on tar reforming (Jordan and Akay, 2013).

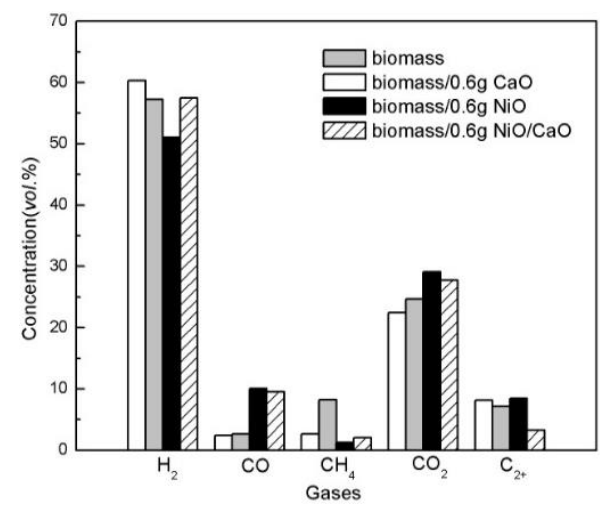

(a)

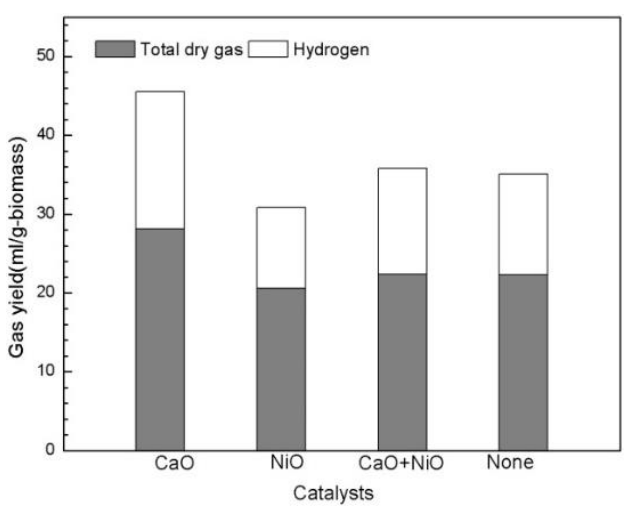

(b)

Figure 4. Effect of additive on biomass pyrolysis. (a) Gas composition; (b) Gas yield; Biomass weight was $3 \mathrm{~g}$, heating rate was $15^{\sim} 19^{\circ} \mathrm{C} \mathrm{min}^{-1}, \mathrm{~T}=700{ }^{\circ} \mathrm{C}$, additive/biomass was $20 w t$. \%

Fig. 4 shows the effect of additive type on pyrolysis of fresh biomass. As can be seen that highest $\mathrm{CO}$ concentration (around 10vol. \%) was obtained with the case of $\mathrm{NiO}$ 
addition, followed by $\mathrm{NiO} / \mathrm{CaO}$. Meanwhile, $\mathrm{CO}$ concentration was lowered when biomass co-pyrolysis with $\mathrm{CaO}$. Hydrogen concentration was highest (about $61 \mathrm{vol} . \%)$ when $\mathrm{CaO}$ was added, and at the meantime $\mathrm{NiO}$ showed lower activity toward hydrogen production. Methane concentration was highest for pure biomass, around $9 \mathrm{vol}$. \%, and lowest for biomass with $\mathrm{NiO}$ (only about $2 \mathrm{vol}$. \%). Carbon dioxide content was slightly decreased because of $\mathrm{CaO}$ addition. Biomass with $\mathrm{CaO} / \mathrm{NiO}$ showed a compromised gas composition between that of biomass with $\mathrm{CaO}$ and $\mathrm{NiO}$ only. Fig. 4(b) demonstrated the gas yield through pyrolysis of biomass with different additives. Pyrolysis of pure biomass got total dry gas of around $22 \mathrm{ml} \mathrm{g}^{-1}$-biomass. It was increased by $27 \%$ when biomass pyrolysis with $\mathrm{CaO}$. Hydrogen yield was highest for the case of $\mathrm{CaO}$ addition, and lowest for that with $\mathrm{NiO}$. The hydrogen yield decreased as the order following: [biomass $+\mathrm{CaO}]>[$ biomass $+\mathrm{CaO} / \mathrm{NiO}]>$ pure biomass $>$ [biomass+NiO].

$\mathrm{CaO}$ showed highest activity toward hydrogen production, and at the same time, with lowest $\mathrm{CO}_{2}$ concentration. This result can be due to the enhanced WGS during pyrolysis of biomass with $\mathrm{CaO}$ (Guan et al., 2007; Florin and Harris, 2008). The reactions take place during pyrolysis in presence of $\mathrm{CaO}$ can be written as following:

Biomass $\rightarrow \mathrm{H}_{2} \mathrm{O}+\mathrm{CO}+\mathrm{H}_{2}+\mathrm{CO}_{2}+\mathrm{C}_{x} \mathrm{H}_{y} \ldots$ endothermic

$$
\begin{aligned}
& \mathrm{CO}+\mathrm{H}_{2} \mathrm{O} \rightarrow \mathrm{CO}_{2}+\mathrm{H}_{2}+41 \mathrm{~kJ} \mathrm{~mol}^{-1} \\
& \mathrm{CO}_{2}+\mathrm{CaO} \rightarrow \mathrm{CaCO}_{3}-178 \mathrm{~kJ} \mathrm{~mol}^{-1}
\end{aligned}
$$

According to Le-chattier principle, a reaction would move forward if the partial pressure of the product is less than the partial pressure of reactant (Acharya et al., 2010). In the reactor, $\mathrm{CO}_{2}$ released during pyrolysis was captured by $\mathrm{CaO}$ according to reaction (17). This reaction led to decrease of $\mathrm{CO}_{2}$ partial pressure, and resulted in promotion of reaction (16) to the forward direction.

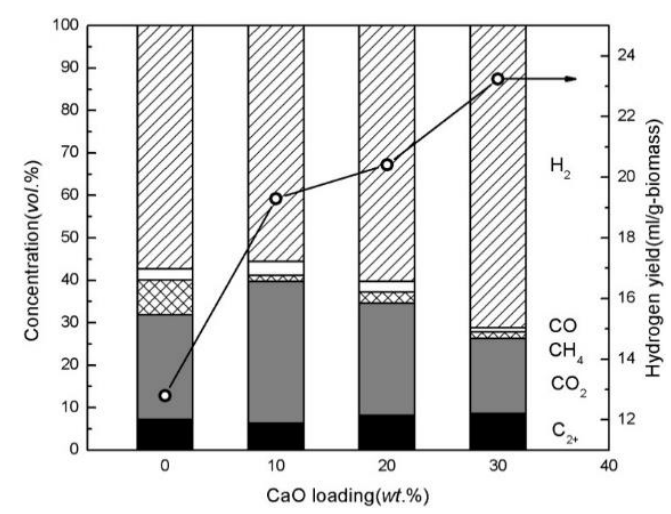

Figure 5 Effect of $\mathrm{CaO}$ loading on pyrolysis of fresh biomass.Biomass weight was $3 \mathrm{~g}$, heating rate was $15^{\sim} 19^{\circ} \mathrm{C} \mathrm{min}{ }^{-1}, \mathrm{~T}=700^{\circ} \mathrm{C}$
$\mathrm{NiO}$ could only play the role as catalyst during pyrolysis, its activity was decreased likely due to large content of moisture and lower temperature in the system. In the meantime, reduction of $\mathrm{NiO}$ during pyrolysis caused consumption of reducing gases, such as $\mathrm{H}_{2}$ and $\mathrm{CO}$. Thus, $\mathrm{NiO}$ alone showed no promotion on hydrogen production.

To study the effect of calcium oxide loading on gas composition and gas yield, experiments were done for $\mathrm{CaO} /$ biomass mass ratio of $0,0.1,0.2$ and 0.3 and the results were shown in Fig. 5.

By increasing $\mathrm{CaO} /$ biomass from $0 w t$. \% to $30 w t$. \%, the volumetric composition of hydrogen was genarally increased. The highest hydrogen concentration was noted when $\mathrm{CaO} /$ biomass was $30 w t$. $\%$ with a value of about $70 \mathrm{vol}$. \%. The yield of hydrogen also increased with $\mathrm{CaO}$ loading, and it was nearly doubled (from 12.7 to 23.2 $\mathrm{ml} \mathrm{g}^{-1}$-biomass) as $\mathrm{CaO} /$ biomass mass ratio rose from 0 to 0.3 . When $\mathrm{CaO} /$ biomass was $10 \mathrm{wt}$. $\%$, it was interesting to observe that the percentage of carbon dioxide in dry gas was increased by almost $8 \mathrm{vol}$. \% compared with that of Owt. \% addition. Futher higher $\mathrm{CaO}$ loading, the $\mathrm{CO}_{2}$ concentration gradually decreased. $\mathrm{CaO}$ appears to have catalytic behavior to break the tar and result in higher gas yield (Luo et al., 2009). The suitable explaination could be that $10 w t$. $\%$ of $\mathrm{CaO}$ preferentially played a role of catalyst for the sharply reduction of methane concentration (from $10 \mathrm{vol}$. \% with $\mathrm{CaO} /$ biomass $=0 \mathrm{wt}$. $\%$ to $1.5 \mathrm{vol}$. \% with $\mathrm{CaO} /$ biomass $=10 w t$. \%). The higher hydrogen yield in $\mathrm{CaO} /$ biomass of $10 w t$. \% should be resulted from the higher total dry gas yield, although percentage of hydrogen showed a slight decrease compared with that from pyrolysis of pure biomass. Higher $\mathrm{CaO} /$ biomass mass ratio could be helpful in production of hydrogen, not only because the enhanced WGS reaction but also the catalytic effect. On the other hand, the carbonation reaction (Eq. (3)) is exothermic and when it captures carbon dioxide it releases lots of heat at the same time which could benefit the process. The higher temperature results in an improvement in cracking of tar and converting of char (Jiang et al., 2012)

\section{Conclusions}

Pyrolysis experiments of fresh biomass (moisture content was nearly $70 w t$. \%) were conducted in a TGA setup and a fixed-bed reactor system. Activation energy of pyrolysis of fresh biomass was $29.8 \mathrm{~kJ} \mathrm{~mol}^{-1}$ and with a reaction order around 1. Addition of $\mathrm{CaO}$ lowered the weight loss in moisture release stage and led to form $\mathrm{Ca}(\mathrm{OH})_{2}$. Activation energy of pyrolysis was lowered to $20.4 \mathrm{~kJ} \mathrm{~mol}^{-1}$ and resulted in an additional reduction in weight in temperature range of $382 \sim 490{ }^{\circ} \mathrm{C}$ when $\mathrm{CaO}$ was added. Higher temperature benefited biomass pyrolysis and produced more hydrogen. $\mathrm{CaO}$ showed better activity toward hydrogen production than $\mathrm{NiO}$, but $\mathrm{NiO}$ showed higher catalysis on methane conversion. CaO/biomass of $30 w t$. \% displayed the highest hydrogen yield. Hydrogen 
concentration in dry gas from pyrolysis of fresh biomass displayed apparently high value which proved the possibility of hydrogen production directly from fresh biomass pyrolysis.

\section{Acknowledgements}

The authors would like to thank the financial supports of Natural Science Foundation of China with Project No.51206200, and Natural Science Foundation of Chongqing (CSTC2013jjB0021), and visiting Scholar Foundation of Key Lab. of Low-grade Energy Utilization Technologies and System, MOE of China in Chongqing University (LLEUTS-201301).

\section{References}

Ansari M.H., Jafarian S., Tavasoli A., Karimi A. and Rashidi M. (2014), Hydrogen rich gas production via nano-catalytic pyrolysis of bagasse in a dual bed reactor, Journal of Natural Gas Science and Engineering, 19, 279-286.

Alvarez J., Kumagai S., Wu C.F., Yoshioka T., Bilbao J., Olazar M. and Williams T.P. (2014), Hydrogen production from biomass and plastic mixtures by pyrolysis-gasification, International Journal of Hydrogen Energy, 39, 10883-10891.

Acharya B., Dutta A. and Basu P. (2010), An investigation into steam gasification of biomass for hydrogen enriched gas production in presence of $\mathrm{CaO}$, International journal of hydrogen energy, 35, 1582-1589.

Bulushev D.A. and Ross J.R.H. (2011), Catalysis for conversion of biomass to fuels via pyrolysis and gasification: A review, Catalysis Today, 171, 1-13.

Çağlar A. and Demirbaş A. (2002), Hydrogen rich gas mixture from olive husk via pyrolysis, Energy Conversion and Management, 43,109-117.

Corella J., Toledo J.M. and Padilla R. (2004), Catalytic hot gas cleaning with monoliths in biomass gasification in fluidized beds. 1. Their effectiveness for tar elimination, Industrial \& Engineering Chemistry Research, 43, 2433-2445.

Florin N.H. and Harris A.T.(2008), Enhanced hydrogen production from biomass with in situ carbon dioxide capture using calcium oxide sorbents, Chemical Engineering Science, 63, 287-316.

Guan J., Wang Q., Li X., Luo Z. and Cen K.(2007), Thermodynamic analysis of a biomass anaerobic gasification process for hydrogen production with sufficient $\mathrm{CaO}$, Renewable Energy, 32, 2502-2515.

Han L., Wang Q.H., Yang Y.K., Yu C.J., Fang M.X. and Luo Z.Y. (2011), Hydrogen production via $\mathrm{CaO}$ sorption enhanced anaerobic gasification of sawdust in a bubbling fluidized bed, International journal of hydrogen energy, 36, 4820-4829.

Hao Q.L., Wang C., Lu D.Q., Wang Y., Li D. and Li G. (2010), Production of hydrogen-rich gas from plant biomass by catalytic pyrolysis at low temperature, International Journal of Hydrogen Energy, 35, 8884-8890.

Jiang H.T., Wu Y.R., Fan H. and Ji J.B. (2012), Hydrogen Production from Biomass Pyrolysis in Molten Alkali, AASRI Procedia, 3, 217-223.

Jordan C.A. and Akay G. (2013), Effect of CaO on tar production and dew point depression during gasification of fuel cane bagasse in a novel downdraft gasifier, Fuel Processing Technology, 106, 654-660.

Kuan W.H., Huang Y.F., Chang C.C. and Lo S.L. (2013), Catalytic pyrolysis of sugarcane bagasse by using microwave heating, Bioresource Technology, 146, 324-329.
Liu S.M., Zhu J.L., Chen M.Q., Xin W.P., Yang Z.L. and Kong L.H. (2014), Hydrogen production via catalytic pyrolysis of biomass in a two-stage fixed bed reactor system, International Journal of Hydrogen Energy, 25, 13128-13135.

Luo S.Y., Xiao B., Guo X.J., Hu Z.Q., Liu S.M. and He M.Y. (2009), Hydrogen-rich gas from catalytic steam gasification of biomass in a fixed bed reactor: influence of temperature and steam on gasification performance, Technical Communication, International Journal of Hydrogen Energy, 34, 1260-1264.

Nasir Uddin M., Wan Daud W.M.A. and Abbas H.F. (2013), Potential hydrogen and non-condensable gases production from biomass pyrolysis: Insights into the process variables, Renewable and Sustainable Energy Reviews, 27, 204-224.

Nowakowski D.J., Jones J.M., Brydson R.M.D. and Ross A.B. (2007), Potassium catalysis in the pyrolysis behavior of short rotation willow coppice, Fuel, 86, 2389-2402.

Sutton D., Kelleher B. and Ross J.R.H. (2001), Review of literature on catalysts for biomass gasification, Fuel Processing Technology, 73, 155-173.

Veses A., Aznar M., Martínez I., Martínez J.D., López J.M., Navarro M.V., Callén M.S., Murillo R. and García T. (2014), Catalytic pyrolysis of wood biomass in an auger reactor using calciumbased catalysts, Bioresource Technology, 162, 250-258.

Zhang L., Zhang B., Yang Z.Q. and Yan Y.F. (2014), Pyrolysis Behavior of Biomass with Different Ca-based Additives, RSC Adv, 4, 39145-39155.

Zhang L., Zhang B., Yang Z.Q. and Guo M.N. (2015), The Role of Water on the Performance of Calcium Oxide-Based Sorbents for Carbon Dioxide Capture: A Review, Energy technology, 1, 10-19. 